\title{
A Computing Program for Scientists and Engineers - What is the Core Of Computing?
}

\author{
Ralf Denzer \\ Environmental Informatics Institute; P.O. Box 11 12, 69251 Gaiberg, Germany; \\ Ralf.Denzer@enviromatics.org
}

\begin{abstract}
The education of non computer scientists in Information Technology basics becomes more important every day. We currently see a number of related effects in the educational and job market that force us to think about the requirements of minimal IT education for an engineer or a scientist. This paper, through a case study, raises questions related to these issues. The case study is a Curriculum on Environmental Informatics, which has been developed by the author and others under a grant by the European Union and the Canadian government. From this example, the paper tries to discuss the most important common roots in IT for engineers and scientists under heavy time constraints in their IT education. It will also reflect back on what this means for "pure" computer scientists.
\end{abstract}

Keywords: Computer Science Curricula, Enviromatics, EU Canada Program in Higher Education and Training

\section{COMPUTING CURRICULA FOR COMPUTER SCIENTISTS AND NON COMPUTER SCIENTISTS}

Computing curricula come in very different flavours across the world of higher education. Depending on the actual focus of an individual program, they are called Computer Science (CS), Information Technology (IT), Information Science (IS), Scientific Computing (SC), only to mention some of them. Although these terms are not clearly defined, and are often used

The original version of this chapter was revised: The copyright line was incorrect. This has been corrected. The Erratum to this chapter is available at DOI: 10.1007/978-0-387-35619-8_15 
differently and contradictorily in different countries, they usually imply a certain common understanding of the particular focus of the program. An example is the common understanding that CS is usually a "hard" scientific program based on a detailed discussion of computer science theory, while IS is a more "soft" program with different scientific standards. All these programs are needed for different areas of computing applications and different types of personnel in the job market and in the scientific community. A Common Basis for Programs in Computing would hence discuss those aspects of these programs that are the common core of these different programs in computing.

This paper has a different scope. The case study presented illustrates the needs of an IT education for non IT professionals, in particular for engineers and scientists, based on the experiences of more than 5 years of international collaboration in a Curriculum on Environmental Informatics [1], or Enviromatics [2].

Although the focus of these discussions is not primarily on computer scientists, we are convinced that the results can feed back to the "pure" computer science curricula as well. We develop software for users and these users are often a neglected part of the system.

\section{COMPUTING FOR NON COMPUTER SCIENTISTS}

There are three main reasons why we need to deal with computing curricula content for non computer scientists today. First, there is no scientific or engineering education today that would not require a basic understanding of computing. Often scientists and engineers become second career software developers. Second, there are many tools (like RDBMS with graphical front ends) that make it (supposedly) easy to develop an information system. Without the background knowledge of software engineering, untrained users of such tools often do a lot of nonsense. Third, the interface between the computer scientist and a "pseudo-trained" end user, often overestimating his or her understanding, is an issue we have to deal with today.

The two main questions evolving from these issues, which we wish to discuss in this article, are the following: a) If we are going to do a limited computing training of scientists and engineers, in what should we train them?; and b) What is particularly useful in the training of non computer scientists and in the training of computer scientists in order to make their interface in real life better? 


\section{CASE STUDY: COMPUTING FOR ENVIRONMENTAL SCIENTISTS AND ENGINEERS}

Environmental protection is now unthinkable without the use of information systems and software tools for complex decision making processes. Many national and international organizations have been and still are building databases of environmental measurements and decision support software, e.g. for environmental impact assessment. Starting in the mid1980's, a new applied discipline in Computer Science - which we now call Environmental Informatics or Enviromatics - evolved very quickly. In IFIP, it is represented by WG 5.11 of TC 5 (see www.enviromatics.org).

Due to the complexity and wide ranging aspects of such systems, we are still heterogeneous in our teaching activities which can be thought of as a basis for Environmental Informatics education. The extreme broadness of the application area on the one hand side and the many possibilities of software support on the other side means that it is very difficult for anybody to teach an Environmental Informatics course alone today. Environmental Informatics involves environmental monitoring, remote sensing, compliance, supervision by government agencies and other authorities, environmental research, planning, lifecycle assessment, etc. to mention some of them. The software side draws on scientific databases, visualization, modelling and simulation, artificial intelligence techniques as well as information retrieval and delivery over networks like the Internet. Environmental data management and environmental information systems have to bridge gaps in time and space in data, information and knowledge. Elements of modelling, statistical computing, scientific database, visualization, environmental statistics (including risk assessment), uncertainty estimation and management, integration of heterogeneous and legacy systems and knowledge engineering all contribute to a better understanding of environmental problems.

From 1997 to 2000, a group of European and Canadian universities conducted a project named ECCEI (EU Canada Curriculum on Environmental Informatics), which was funded under the EU Canada Program on Higher Education and Training. The goal of this project was (in addition to student and faculty exchange) the development of a curriculum for environmental information and decision support systems. With the curriculum, we intended to address computer scientists and environmental scientists and engineers.

A major problem in organizing the material was the ordering of the course modules. We discussed whether it is appropriate to use a primary order derived from IT technologies or one from environmental topics, the 
application areas. We finally came up with a curriculum design that progresses from less complex to more complex tasks, i.e. that follows the direction of more high level, abstract information generated by the information system. Table 1 shows the content of the curriculum.

If you add up the necessary hours to get only an overview of every topic, you end up with 120 to 150 hours of instruction. Clearly, each of the topics can be a course by itself and in that case, the curriculum would result in an environmental information systems specialist. Realistically, we are unable to teach all the topics in one course, even if it was a very big one. As far as we know, there is no EIS program either (world wide), which would offer such a curriculum as a BA or MA.

Our approach to cope with this situation was a rather unconventional method of teaching the course. Between 1997 and 2000, we taught no fewer than nine short courses with students from Germany, Canada, Italy and France. These courses typically extend over one week, host between 20 and 40 students and 5 to 10 faculty, each of them a specialist in more than one of the curricula topics. Most of the courses were taught in a specific location in Austria, an alpine farm house in a Nature Park, which offered us the possibility to set up seminar and computer lab facilities, conduct practical case studies and collect a lot of area related data over the years. After the three years of government funding, we continued with a core group from Canada, Germany and France and could also involve new partners from Austria and the United States.

The course starts with the definition of several projects (e.g. planning of a ski resort, assessment of flood risks in the valley or a public visual information system), which are then conducted in interdisciplinary teams. Typically, each team consists at least of one member from each participating university and of a mix of computer science students and environmental students. Theoretical parts are taught "on the fly", e.g. if one or more projects end up in a situation in which they need more background on certain methods or tools. After five days, the result of each team is expected to be a study, a methodology or (in most cases) a piece of software. 
Table 7. ECCEI Curriculum

\section{PART I: WHY ENVIROMATICS ?}

1. History of Enviromatics Developments

2. Application Areas

3. Introduction into the ECCEI Course

4.Introduction into the Common Example

\section{PART II: ENVIROMATICS BASE METHODS}

SECTION II.A Problem Definition and

System Analysis

5. Problem Definition

6. System Analysis

\section{SECTION II.B Data Management and} Information Modelling

7. Environmental Data, Data Preparation and Acquisition

8. Monitoring

9. Environmental Databases and

Environmental Information Systems (EIS)

10. Information Modelling

11.Meta Information in Environmental

Databases

\section{SECTION II.C Data Analysis}

12. Environmental Statistics

13. Geographical Information Systems

14. Visualization
SECTION II.D Diagnosis and Interpretation

15. Environmental Risk and Impact

Assessment

16. Environmental Models

17. Environmental Indicators

18. Diagnosis and Artificial Intelligence

SECTION II.E Decision Support

19. Target Groups for Decision Support

20. IT Techniques and Systems for Decision

Support

21. Scenarios

22. Presentation in DSS

\section{PART III: ENVIROMATICS INTEGRATION METHODS}

\section{SECTION III.F EIS Interoperability}

23. Integration Problems

24. Environmental Data Standards

25.Building and Managing Environmental Data Networks

SECTION III.G Meta Information Systems

26. Properties of Meta Information

27. Environmental Data Catalogs

28. Environmental Catalogs on the World Wide Web

29. Multilingual Information Systems

SECTION III.H Open EIS Architectures

30. Properties of Open EIS Architectures

31. Review of Architectures

32. Generic EIS Infrastructures 


\section{EXPERIENCES, DISCUSSIONS AND CONCLUSIONS}

From the results and the interaction of our numerous courses, we have drawn the following main conclusions:

1. The most important and most effective module we teach to non computer scientists is basic information system modelling. Once these students get a minimal understanding of consistency, redundancy and complexity in information systems, and why computer scientists must use structured methods in their design to deal with these issues, they have a completely different perspective of information technology.

2. The most important aspect to learn for the computer scientists is that there are unstructured fields of knowledge (like environmental sciences) that lack a lot of the logic they are taught. One professor created the analogy of showing them that "the world is not a square box".

3. The most important overall experience of the courses is the interaction between groups, the human aspect. In many computing programs, there is no interaction of the students with real world users at all. In our courses, we create a real life project environment, which the students never see in our universities.

Coming back to the two questions introduced in section 2: a) We are strongly convinced that a minimum IT curriculum for scientists and engineers must contain issues of sound software engineering, before anything else; b) The joint interactive training of both groups together is a most useful vehicle for their later professional life. Teaching non computer scientists basic understanding of information system modelling (like ERMs) helps in communication between the groups.

\section{SHORT BIOGRAPHY OF THE AUTHOR}

Dr. Ralf Denzer is a professor for computer science in Saarbrücken, Germany. His main research area is distributed and open systems. Together with his colleague, Reiner Güttler, he is the director of the Environmental Informatics Group (www.enviromatics.net), an institute which has been working on more than 70 environmental information system projects, with a focus on integration of distributed information systems. He is chairman of the international Environmental Informatics Institute (www.enviromatics.de) and chairman of IFIP Working Group 5.11, Computers and Environment (www.enviromatics.org). He is adjunct professor at the University of 
Guelph, On, Canada and adjunct professor at James Madison University, Va, USA.

\section{REFERENCES}

[1] D. A. Swayne, R. Denzer, Teaching EIS Development - The EU Canada Curriculum on Environmental Informatics, Environmental Software Systems Vol. 3 (2000) Environmental Information and Decision Support, pp. 152-156, Kluwer Academic Publishers

[2] R. Denzer, Environmental Software Systems, Encyclopedia of Computer Science and Technology, Vol. 40(25), pp. 51-61, Marcel Dekker Publishers, 1999 